\section{PO-0237 THE IMMUNMODULATORY EFFECTS OF ACTIVE VITAMIN D3 ON SALMONELLA COLITIS IN MICE}

${ }^{1} \mathrm{H}$ Fu-Chen, ${ }^{2} \mathrm{H}$ Shun-Chen. ${ }^{1}$ Pediatrics, Kaohsiung Chang Gung Memorial Hospital and Chang Gung University, Kaohsiung, Taiwan; 'Pathology, Kaohsiung Chang Gung Memorial Hospital, Kaohsiung, Taiwan

\subsection{6/archdischild-2014-307384.888}

Salmonella spp. remain major public health problems for the whole world. A better understanding of pathogenesis of these food-borne pathogens is a prerequisite for the design of improved intervention strategies that could reduce the use of antimicrobial agents and drug-resistant Salmonellosis.

Increasing studies suggested 1,25-dihydroxyvitaminD3 $(1,25 \mathrm{D} 3)$, the active form of vitamin D, was effective in ameliorating colitis via the lumen of the intestinal tract. Stimulation of NOD2 expression by 1,25D3-stimulated antimicrobial peptides production enhancing autophagy imply that vitamin D would boost autophagy. Therefore, we aims to investigate the effect of active vitamin D3 on the severity of Salmonella colitis.

Salmonella colitis model was conducted with 6-8 wk-old male C57BL/6 mice: Streptomycin -pretreated C57BL/6 mice were mock infected with sterile PBS or infected orally with $S$. Typhimurium wild-type strain SL1344 for48 h. Mice were randomly assigned to control, model and $1,25(\mathrm{OH})_{2} \mathrm{D}_{3}$ treated group. At the end of the experiment, mice were sacrificed; tissue samples from the intestinal tracts, spleens, and livers were removed for analysis of bacterial colonisation, Western blot for proteins expression, and RTPCR for mRNA expression.

We observed 1, 25D3 reduced the severity of Salmonella colitis in $\mathrm{CH} 57 \mathrm{~B} / 6$ mice by reducing cecal mIL-1beta $(79.36 \pm$ 24.60 vs. $271.40 \pm 60.88, \mathrm{p}<0.01)$, mIL-6 (206.32 \pm 52.18 vs. $491.74 \pm 39.44, \mathrm{p}<0.005)$ and mTNF-alpha $(44.18 \pm$ 17.24 vs. $129.93 \pm 18.05, \mathrm{p}<0.005)$ mRNA expression, bacterial colonisation (CFU/mg tissue) in liver $\left(1.02 \pm 0.20^{\prime} 10^{2}\right.$ vs. $\left.4.97 \pm 0.66^{\prime} 10^{2}, \mathrm{p}<0.001\right)$ and spleen $\left(1.50 \pm 0.42^{\prime} 10^{2}\right.$ vs. $\left.45.4 \pm 3.56^{\prime} 10^{2}, \mathrm{p}<0.0001\right)$, but enhanced the autophagy expression in Western blot, comparing to SL1344 infection only.

In conclusion, active vitamin D3 could reduce Salmonella colitis by reducinginflammation and bacterial colonisation via autophagy induction.

\section{PO-0238 BIOCHEMICAL AND IMMUNOLOGICAL MARKERS OF MEASLES WITH HELMINTHIASIS IN THE CHILDREN}

OM Horlenko, MA Polyak. Pediatric with Infectiuos Diseases, Uzhgorod National University Medical Faculty, Uzhgorod, Ukraine

\subsection{6/archdischild-2014-307384.889}

Background and aims Duration of Measles in association with Helminthiasis $(\mathrm{MwH})$ in the children is insufficiently studied and requires more research is.

Methods We investigated of biochemical and immunological markers in the children with $\mathrm{MwH}$. We observed 87 children (age $3.12 \pm 1.24$ years) with a primary diagnosis of Measles and associated worm infestation (ascariasis and trichuriasis) on the bases of Regional Infectious Hospital, Uzhgorod, Ukraine. These biochemical and immunological parameters were compared with the dates of control group (Measles without of Helminthiasis).

Results $\mathrm{MwH}$ children characterised prevalence following parameters: higher alpha -amylase $(\mathrm{p}<0.01)$, glucose $(\mathrm{p}<$ $0.001)$, GGT $(\mathrm{p}<0.001)$ and alkaline phosphatase $(\mathrm{p}<0.001)$. Also dominated indicators of ALT $(44,50 \pm 8,21 \mathrm{U} / \mathrm{L}, \mathrm{p}<0.05)$,
AST $(64,92 \pm 2,83 \mathrm{U} / \mathrm{L}, \mathrm{p}<0.001)$ and thymol $(5,21 \pm 0,29$ IU, $\mathrm{p}<0.001)$, on the basis of what we can concluded about the complications of Measles infection by reactive hepatitis. We indeficated increase of level of IL-2 in 5.5 times to the control group ( $\mathrm{p}<0.001)$, IL-6 in 25-time ( $\mathrm{p}<0,001)$, IL-10 in 1.7 time $(\mathrm{p}<0.001)$. The levels of microelements of blood serum? were lower: iodine $(\mathrm{p}<0.001)$, copper $(\mathrm{p}<0.001)$, zinc $(\mathrm{p}<$ 0.001 ) by our study. Phosphorus level was higher in the group of children with the Measles in association with Helminthiasis ( $\mathrm{p}$ $<0.001$ ). The mikro elements parameters of urine were lower in the study group: iron $(\mathrm{p}<0.001)$, copper $(\mathrm{p}<0.001)$, zinc $(\mathrm{p}<$ $0.001)$ and iodine $(\mathrm{p}<0.001)$. Level of phosphorus were increased $(\mathrm{p}<0.001)$.

Conclusions The dates of our investigation in the children diagnosed with Measles in association with Helminthic infestation presented significant increase of inflammation markers and an imbalance of mineral metabolism.

\section{PO-0239 A MYSTERY OF INFECTOLOGY : BRAIN ABSCESS IN A CGD PATIENT}

1'K Kalocsai, 'T Pék, 'Z Liptai, ${ }^{2} \mathrm{G}$ Rudas. ${ }^{1}$ Pediatric Infectology, Szent László Municipal Hospital for Infectious Diseases, Budapest, Hungary; ${ }^{2}$ MR Research Center, Semmelweis University, Budapest, Hungary

\subsection{6/archdischild-2014-307384.890}

CGD is an immunodeficiency caused by mutations in genes encoding subunits of the NADPH oxidase complex. Normally, assembly of the NADPH oxidase complex in phagosomes of phagocytic cells leads to a "respiratory burst" essential for the clearance of microorganisms. CGD patients lack this mechanism, which results in life-threatening bacterial and fungal infections and granuloma formations. The leading cause of death are pneumonia and pulmonary abscess, septicemia and brain abscess. In neurogical manifestations various pathogens have been involved including Aspergillus spp., S. prolificans, A. infectoria, Salmonella and Staphylococcus spp. There are only some several reports on fungal brain and spinal cord infection due to Candida spp. To decrease mortality and morbidity from fungal infections the prophylactic use of itraconazole or voriconazole is widely recommended. A relatively new azole, posaconazole is active in pulmonary and cerebral fungal manifestations, indeed may be effective against fungi with inherent resistance to $\mathrm{AmpB}$ or voriconazole. In the past twenty years we have managed seven children with CGD. We present a two - year history of an X-linked CGD patient with brain abscess. In spite of our effort we were unable to identify any causative pathogen. The brain abscess did not respond to conventional antibacterial and antifungal treatment for a long time. Based on the findings and literature data we presumed the causative agent might be some kind of moulds. We suppose the use of echinocandin and posaconazole as salvage ("prophylactic") therapy. It has resulted significant regression of the brain abscess.

\section{PO-0240 IMAGING IN CHILDREN WITH ACUTE OSTEOMYELITIS; IS CONVENTIONAL IMAGING NEEDED?}

M Khalifa', M Al-Janahi ${ }^{2}$, A Al-Hammadi ${ }^{3}$, L Al-Naimi ${ }^{3}$, M Al-Qadi ${ }^{3},{ }^{3}$ M Sami. ${ }^{1}$ General Pediatrics, Hamad Medical Corporation, Doha, Qatar; ${ }^{2}$ Pediatric Infectious Disease, Hamad Medical Corporation, Doha, Qatar; ${ }^{3}$ General Pediatric, Hamad Medical Corporation, Doha, Qatar

10.1136/archdischild-2014-307384.891 